\title{
HUBUNGAN KOMUNIKASI TERAPEUTIK PADA PEMASANGAN INFUS DENGAN KEPUASAN PASIEN
}

\author{
Irawati*, Endang Subandi**, Asiah***
}

\begin{abstract}
ABSTRAK
Komunikasi perawat dengan klien di beberapa pelayanan kesehatan khususnya rumah sakit hanya berfokus pada tugas, sehingga gagal menyediakan perawatan informasi. penelitian tentang hubungan komunikasi terapeutik pada pemasangan infus dengan kepuasan pasien di Ruang UGD Rumah Sakit Tentara Ciremai Kota Cirebon tahun 2013. Tujuan penelitian ini untuk mengetahui hubungan komunikasi terapeutik pada pemasangan infus dengan kepuasan pasien di Ruang UGD Rumah Sakit Tentara Ciremai Kota Cirebon. Jenis penelitian menggunakan deskriptif korelasi. seluruh yang di infus di Ruang UGD Rumah Sakit Tentara Ciremai Kota Cirebon pada bulan April 2013. Teknik sampel dilakukan dengan menggunakan rumus minimal sample size kemudian pengambilan sampel dilakukan secara random, berjumlah sampel 78 orang. Instrumen penelitian menggunakan kuesioner, sebelum digunakan terlebih dahulu dilakukan uji validitas dan reliabilitas. Teknik analisa data terdiri dari analisa univariat dan bivariat. Hasil penelitian menunjukan bahwa gambaran pelaksanaan komunikasi terapeutik berada kategori cukup berjumlah 33 orang (42,3\%). Gambaran kepuasan pasien berada pada kategori Puas berjumlah 40 orang $(51,3 \%)$. Ada hubungan pelaksanaan komunikasi terapeutik pada pemasangan infus dengan kepuasan pasien di Ruang UGD Rumah Sakit Tentara Ciremai Kota Cirebon tahun 2013 dengan $\chi_{\text {hitung }}^{2}(18,545)>\chi_{\text {tabel }}^{2}(12,6)$ dan $\rho$ value $=0,005(\rho<0,050)$.
\end{abstract}

Kata Kunci : komunikasi terapeutik, kepuasan, pemasangan infus

\begin{abstract}
Nurse communications with the patient in several health services especially in hospital are just focusing in their job descriptions; it makes informational incompleteness care to be provided. This research is study about the relationship between the therapeutic communications of infusion installation with the patient satisfaction in emergency room of RST Ciremai Cirebon in 2013. The purpose of this research is to know about the relationship between the therapeutic communications of infusion installation with the patient satisfaction in emergency room of RST Ciremai Cirebon This research using descriptive correlation analytic method from all the patients in the emergency room of RST Ciremai Cirebon who had infusion installation, within April 2013. Sampling technique taken by minimizes sampling size and randomly taken, total samples are 78 persons. Questioners were used as a research instrument, which has passed validity and reliability test before. Univariate and bivariate data analysis were used as a data analytic technique. From this research comes a results that the implementation of therapeutic communications is in "enough" level for 33 person or $42.3 \%$ and in "satisfied" level for 40 persons or $51.3 \%$. There are found relationship between the implementation of therapeutic communication in infusion installation with the patient satisfaction in emergency room of RST Ciremai Cirebon in 2013 with $\chi 2$ count $(18,545)>\chi 2$ tabel $(12,6)$ and $\rho$ value $=0,005(\rho<0,050)$.

Keyword : therapeutic communication, satisfaction, infusion installation
\end{abstract}

\footnotetext{
* Alumni PSKM STIKes Cirebon Lulus Tahun 2013

** Staf Pengajar Program Studi DIII Keperawatan STIKes Cirebon

*** Staf Pengajar Program Studi Profesi Ners STIKes Cirebon
} 


\section{PENDAHULUAN}

Rumah sakit merupakan tempat penyelenggaraan pelayanan kesehatan menyeluruh yang dipadukan dengan penggunaan teknologi kedokteran dan keperawatan terkini sehingga rumah sakit merupakan tempat tumpuan harapan manusia untuk dapat hidup sehat. ${ }^{1}$ Dalam upaya memenuhi harapan pasien maka rumah sakit harus menyelenggarakan pelayanan kesehatan yang bermutu.

Pengukuran tingkat kepuasan sangat penting dilakukan oleh suatu pelayanan yang bergerak dalam bidang jasa termasuk pelayanan kesehatan khususnya rumah sakit. Dengan melakukan pengukuran tingkat kepuasan pasien, maka dapat diketahui sejauh mana dimensidimensi mutu pelayanan kesehatan yang diberikan dapat memenuhi harapan pasien. ${ }^{2}$

Enam hal yang mempengaruhi kepuasan pasien meliputi: ketepatan waktu, komunikasi terapeutik, keyakinan, kompetensi tekhnis, keterjangkauan, dan hubungan interpersonal. Hubungan interpersonal yang ada merupakan hubungan antara perawat dengan pasien yang berfokus pada aspek psikososial dan keputusan, terutama dalam pengambilan keputusan. Komunikasi merupakan sumber terapeutik yang utama, sehingga komunikasi perawat dapat membantu memahami masalah dan mengidentifikasi masalah pasien. ${ }^{2}$

Komunikasi yang jelas dan tepat penting untuk memberikan asuhan keperawatan yang efektif merupakan tantangan yang unik dalam bidang perawatan kesehatan. Banyak tantangan dalam memberikan perawatan untuk pasien, adanya ragam budaya dan bahasa juga menjadi tantangan dalam bekerja dengan pasien. Komunikasi yang jelas mengenai perawatan dan informasi pasien sama pentingnya. Termasuk kemampuan dalam bentuk interaksi verbal dengan rekan kerja, catatan tertulis, atau publikasi dalam jurnal profesional. ${ }^{1}$

Komunikasi terapeutik berbeda dengan komunikasi sosial, yaitu pada komunikasi terapeutik selalu ada tujuan atau arah yang spesifik untuk komunikasi; oleh karena itu, komunikasi terapeutik adalah komunikasi yang terencana. Komunikasi paling terapeutik berlangsung ketika pasien dan perawat keduanya menunjukkan sikap hormat akan individualitas dan harga diri. ${ }^{2}$

Perawat dituntut untuk melakukan komunikasi terapeutik dalam melakukan tindakan keperawatan agar pasien atau keluarganya mengtahui tindakan apa yang akan dilakukan pada pasien dengan cara perawat harus memperkenalkan diri, menjelaskan tindakan yang akan dilakukan, membuat kontrak waktu untuk melakukan tindakan keperawatan selanjutnya. Kehadiran atau sikap benar-benar ada untuk pasien adalah bagian dari komunikasi terapeutik. Perawat tidak boleh terlihat bingung; sebaliknya, pasien harus merasa bahwa dia merupakan fokus utama perawat selama interaksi. Agar perawat dapat berperan aktif dan terapeutik, perawat harus menganalisa dirinya yang meliputi kesadaran diri, klarifikasi nilai, perasaan dan mampu menjadi model yang bertanggung jawab. Seluruh perilaku dan pesan yang disampaikan perawat hendaknya bertujuan terapeutik untuk pasien. Analisa hubungan intim yang terapeutik perlu dilakukan untuk evaluasi perkembangan hubungan dan menentukan teknik dan ketrampilan yang tepat dalam setiap tahap untuk mengatasi masalah pasien. ${ }^{2}$

Pada saat melakukan tindakan keperawatan terhadap pasien tanpa mendapat penjelasan terlebih dahulu, maka upaya penyembuhan akan kurang berhasil. Hal ini dapat terjadi jika perawat tidak mengetahui pendapat pasien atau pasien menyembunyikan perasaannya. Karena pemberian informasi merupakan usaha perawat yang berdampak terhadap masalah psikologis pasien, maka masalah kesehatan diharapkan tidak terjadi, dengan memberikan informasi yang jelas akan memberikan mental dan prilaku yang lebih baik kepada pasien untuk menghadapi berbagai hal yang ada seperti pada saat pasien di berikan infus, karena pemberian infus merupakan pilihan dan alternative yang kurang di minati oleh pasien. ${ }^{2}$ 
Pemasangan infus merupakan teknik yang mencakup penusukan vena melalui jarum yang di sambungkan. Pemberian cairan infus merupakan salah satu tindakan keperawatan yang sangat sulit dan tidak jarang pasien menolak dan meronta saat akan dilakukan pemasangan infus meskipun frekuensi kejadiannya sangat kecil. Kondisi ini dapat diatasi dengan cara melakukan komunikasi yang bersifat terapeutik untuk menjelaskan manfaat dari tindakan pemasangan infus terhadap pasien sehingga pasien mengetahui. ${ }^{2}$

Pasien akan merasa puas apabila ada persamaan antara harapan dan kenyataan pelayanan kesehatan yang diperoleh. Kepuasaan pengguna pelayanan kesehatan mempunyai kaitan yang erat dengan hasil pelayanan kesehatan, baik secara medis maupun non medis seperti kepatuhan terhadap pengobatan, pemahaman terhadap informasi medis dan kelangsungan perawatan. Kepuasan pasien akan terpenuhi jika komunikasi berjalan dengan baik dimana pasien merasa puas dengan penjelasan petugas keperawatan. ${ }^{3}$

Permasalahan komunikasi yang dihadapi dewasa ini bahwa komunikasi perawat dengan pasien di beberapa pelayanan kesehatan khususnya rumah sakit hanya berfokus pada tugas, sehingga gagal menyediakan perawatan informasi. ${ }^{2}$ Teknik komunikasi terapeutik yang diterapkan perawat terhadap pasien cenderung formal (kaku). Cara perawat membina hubungan komunikasi dengan pasien juga kurang harmonis. Tahapan-tahapan komunikasi terhadap pasien juga tidak dilakukan sebagaimana mestinya. Komunikasi perawat - pasien hanya berfokus pada tugas bukan berfokus kepada pasien yang akibatnya akan mengurangi kualitas komunikasi untuk mengetahui keadaan pasien secara lengkap. ${ }^{2}$

Hasil pelaksanaan studi pendahuluan bertempat di ruang UGD, terhadap 7 pasien yang menjalani hospitalisasi di Rumah Sakit Tentara Ciremai menyatakan bahwa 4 orang (57\%) menyatakan bahwa perawat jarang melakukan komunikasi saat melakukan tindakan perawatan, 2 orang $(29 \%)$ menyatakan saat ditanya tentang keadaan pasien perawat menjawab dengan singkat dan 1 orang (14\%) menyakatan perawat hanya berkomunikasi jika ditanya pasien. Pada umumnya perawat hanya melakukan percakapan singkat untuk memohon ijin bahwa pasien akan dipassang infus dengan percakapan sebagai berikut: "Permisi Pak/Bu, dipasang infus dulu", tanpa memberitahukan apa tujuan, manfaat, dan prosedur apa saja yang akan dilakukan. Pasien hanya diam saja karena tidak mengerti dan tidak berani menanyakan pada perawat yang akan memasang infus.Kondisi ini dimungkinkan karena jumlah pasien yang ditangani dalam jumlah banyak sehingga perawat tidak memungkinkan melakukan komunikasi atau bercakap-cakap dalam waktu yang cukup. Namun demikian kondisi ini bisa berpengaruh terhadap kepuasan pasien mengenai kualitas pelayanan.

Berdasarkan uraian di atas penulis tertarik untuk melakukan penelitian tentang Hubungan Komunikasi Terapeutik Pada Pemasangan Infus dengan kepuasan pasien di Ruang UGD Rumah Sakit Tentara Ciremai Kota Cirebon tahun 2013.

\section{METODE PENELITIAN}

Rancangan pada penelitian ini menggunakan penelitian analitik dengan pendekatan cross sectional. Populasi dalam penelitian ini adalah pasien dewasa yang di infus di Ruang UGD Rumah Sakit Tentara Ciremai Kota Cirebon pada bulan April 2013 berjumlah 408 orang. Sedangkan sampel yang diambil sejumlah 78 orang, dengan menggunakan teknik random sampling yaitu dengan menggunakan teknik minimial sample size dengan rumus sebagai berikut $^{4}: \mathrm{n}=\frac{\mathrm{Z}^{2} \cdot \mathrm{N} \cdot \mathrm{p} \cdot \mathrm{q}}{d^{2}(\mathrm{~N}-1)+\mathrm{Z}^{2} \cdot \mathrm{p} \cdot \mathrm{q}}$

Keterangan :

$\mathrm{n} \quad=$ Besar sampel minimal 


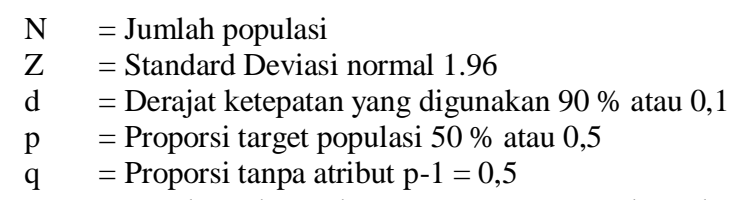

Alat pengumpulan data dengan menggunakan kuesioner, sedangkan analisa yang digunakan adalah analisa univariat dan bivariat.

Analisa univariat pada penelitian ini menggunakan skala persentase dengan rumus sebagai berikut:

\section{Keterangan :}

$$
P=\frac{f}{N} \times 100 \%
$$

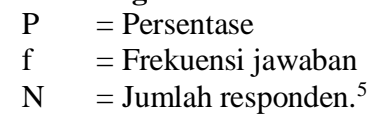

Pada Analisa Bivariat menggunakan chi square

\section{HASIL PENELITIAN \\ Karakteristik Responden}

Berdasarkan hasil penelitian diketahui bahwa sebagian besar responden $(56,45 \%)$ memiliki jenis kelamin laki-laki, sebagian besar responden(67,9\%) memiliki umur pada $>35$ tahun, sebagian besar responden $(47,4 \%)$ memiliki pendidikan pada tingkat SMA, persentase terbesar $(48,7 \%)$ responden mempunyai pekerjaan wiraswasta

\section{Pelaksanaan komunikasi terapeutik pada pada pemasangan infus}

Tabel 1 Pelaksanaan komunikasi terapeutik pada pada pemasangan infus

\begin{tabular}{lcc}
\hline \multicolumn{1}{c}{ Komunikasi Terapeutik } & Frekuensi & Persentase \\
\hline Baik & 27 & $34,6 \%$ \\
Cukup & 33 & $42,3 \%$ \\
Kurang & 18 & $23,1 \%$ \\
\hline Jumlah & 78 & $100 \%$ \\
\hline
\end{tabular}

Berdasarkan tabel diatas dapat diketahui bahwa sebagian besar melakukan pelaksanaan komunikasi terapeutik pada kategori cukup berjumlah 33 responden $(42,3 \%)$.

\section{Kepuasan pasien}

Tabel 2 Distribusi Frekuensi kepuasan pasien

\begin{tabular}{lcc}
\hline \multicolumn{1}{c}{ Kepuasan } & Frekuensi & Persentase \\
\hline Sangat Puas & 11 & $14,1 \%$ \\
Puas & 40 & $51,3 \%$ \\
Kurang Puas & 23 & $29,5 \%$ \\
Tidak Puas & 4 & $5,1 \%$ \\
\hline Jumlah & 78 & $100 \%$ \\
\hline
\end{tabular}

Berdasarkan tabel diatas dapat diketahui bahwa sebagian besar memiliki kepuasan pada kategori puas berjumlah 40 responden $(51,3 \%)$. 


\section{Hubungan pelaksanaan komunikasi terapeutik pada pemasangan infus}

Tabel 3 Crosstabs hubungan pelaksanaan komunikasi terapeutik pada pemasangan infus dengan kepuasan pasien

\begin{tabular}{|c|c|c|c|c|c|c|c|c|c|c|c|c|}
\hline \multirow{3}{*}{$\begin{array}{c}\text { Komunikasi } \\
\text { Terapeutik }\end{array}$} & \multicolumn{8}{|c|}{ Kepuasan } & \multirow{2}{*}{\multicolumn{2}{|c|}{$\begin{array}{c}\text { Total } \\
\text { Jumlah }\end{array}$}} & \multirow{3}{*}{$\chi^{2}$} & \multirow{3}{*}{$\rho$ value } \\
\hline & \multicolumn{2}{|c|}{ Sangat Puas } & \multicolumn{2}{|c|}{ Puas } & \multicolumn{2}{|c|}{ Kurang Puas } & \multicolumn{2}{|c|}{$\begin{array}{l}\text { Tidak } \\
\text { Puas }\end{array}$} & & & & \\
\hline & $\mathrm{n}$ & $\%$ & $\mathrm{~N}$ & $\%$ & $\mathrm{n}$ & $\%$ & $\mathrm{n}$ & $\%$ & $\mathrm{n}$ & $\%$ & & \\
\hline Baik & 8 & $10,3 \%$ & 17 & $21,8 \%$ & 2 & $2,6 \%$ & 0 & $0 \%$ & 27 & $34,6 \%$ & & \\
\hline Cukup & 3 & $3,8 \%$ & 14 & $17,9 \%$ & 14 & $17,9 \%$ & 2 & $2,6 \%$ & 33 & $42,3 \%$ & 18545 & 0005 \\
\hline Kurang & 0 & $0 \%$ & 9 & $11,5 \%$ & 7 & $9,0 \%$ & 2 & $2,6 \%$ & 18 & $23,1 \%$ & 18,543 & 0,003 \\
\hline Tot a l & 11 & $14,1 \%$ & 40 & $51,3 \%$ & 23 & $29,5 \%$ & 4 & $5,1 \%$ & 78 & $100 \%$ & & \\
\hline
\end{tabular}

Berdasarkan hasil analisa statistik di atas, $\chi^{2}$ hitung $(18,545)>\chi^{2}$ tabel $(12,6)$ dan $\rho$ value $=$ $0,005(\rho<0,050)$, maka $\mathrm{H}_{0}$ ditolak. Dapat disimpulkan bahwa ada hubungan pelaksanaan komunikasi terapeutik pada pemasangan infus dengan kepuasan pasien di Ruang UGD Rumah Sakit Tentara Ciremai Kota Cirebon tahun 2013.

\section{PEMBAHASAN}

\section{Pelaksanaan komunikasi terapeutik pada pada pemasangan infus}

Dari hasil penelitian yang dilakukan terhadap 78 responden di ruang UGD Rumah Sakit Tentara Ciremai Kota Cirebon tahun 2013 diketahui bahwa sebagian besar responden menyatakan pelaksanaan komunikasi terapeutik yang dilakukan oleh perawat pada kategori cukup berjumlah 33 responden (42,3\%). Hal ini disebabkan karena perawat yang ada diruang UGD Rumah Sakit Tentara Ciremai telah terbiasa melakukan komunikasi terapeutik kepada pasien dan sudah menjadi standar operasional prosedur sehingga pada saat melakukan tindakan keperawatan selalu didahului dengan komunikasi terapeutik yang baik.

Komunikasi terapeutik merupakan keterampilan dasar untuk melakukan wawancara dan penyuluhan dalam praktek keperawatan. Kegunaan komunikasi terapeutik itu sendiri adalah untuk mendorong dan mengajarkan kerja sama antara perawat dan pasien melalui hubungan perawat pasien. Dimana proses komunikasi yang baik dapat memberikan pengertian tingkah laku pasien dan membantu pasien dalam rangka mengatasi persoalan yang dihadapi. ${ }^{6}$

\section{Kepuasan pasien}

Hasil penelitian yang dilakukan terhadap 78 responden di ruang UGD Rumah Sakit Tentara Ciremai Kota Cirebon tahun 2013 diketahui bahwa berjumlah 40 responden (51,3\%) yang menyatakan puas pada saat pemasangan infus di Rumah Sakit Tentara Ciremai Kota Cirebon, hal ini di sebabkan karena perawat menjelaskan manfaat, tujuan serta dampak apabila tidak dilakukan pemasangan infus.

Kepuasan seseorang (pekerja, pasien atau pelanggan) berarti terpenuhinya kebutuhan yang diinginkan yang diperoleh dari pengalaman melakukan sesuatu, pekerjaan, atau memperoleh perlakuan tertentu dan memperoleh sesuatu sesuai kebutuhan yang diinginkan. ${ }^{7}$

Hasil penelitian ini sesuai juga dengan pendapat Nugroho yang menyatakan bahwa kepuasan adalah suatu tingkatan rasa pasien setelah membandingkan kinerja atau hasil yang dirasakan dibandingkan dengan harapannya. ${ }^{7}$

Pelaksanaan komunikasi terapeutik pada pemasangan infus dengan kepuasan Pasien.

Hasil analisa statistikChi Square diperoleh nilai $\chi_{\text {hitung }}^{2}(18,545)>\chi_{\text {tabel }}^{2}(12,6)$ dan $\rho$ value $=0,005(\rho<0,050)$, maka $\mathrm{H}_{0}$ ditolak. Dapat disimpulkan bahwa ada hubungan 
pelaksanaan komunikasi terapeutik pada pemasangan infus dengan kepuasan pasien di Ruang UGD Rumah Sakit Tentara Ciremai Kota Cirebon tahun 2013.

Responden yang melakukan komunikasi terapeutik terhadap tindakan infus sejumlah 33 responden $(42,3 \%)$ yaitu berkategori cukup, sedangkan responden yang menyatakan puas pada saat pemasangan infus di Rumah Sakit Ciremai Kota Cirebon sebanyak 40 responden $(51,3 \%)$.

Adanya hubungan yang signifikan antara komunikasi terapeutik terhadap tindakan infus dengan kepuasan pasien di Ruang IGD Rumah Sakit Ciremai Cirebon, hal tersebut sesuai dengan teori yang menyatakan bahwa perawat dituntut untuk melakukan komunikasi terapeutik dalam melakukan tindakan keperawatan agar pasien atau keluarganya tahu tindakan apa yang akan dilakukan terhadap pasien. ${ }^{6}$ Penerapan komunikasi terapeutik dalam pelayanan keperawatan oleh perawat dapat meningkatkan hubungan saling percaya, namun penerapan yang tidak efektif dapat mengganggu hubungan yang terapeutik antara pasien dan perawat dan akan berdampak pada ketidakpuasan pasien. Kepuasan pasien sangat berkaitan erat dengan kemampuan komunikasi atau komunikasi terapeutik yang diterapkan perawat dalam berhubungan dengan pasien. Kepuasan pasien itu sendiri adalah hasil penilaian pasien berdasarkan perasaanya, terhadap penyelenggaraan pelyanan kesehatan di rumah sakit yang telah menjadi bagian dari pengalaman atau yang dirasakan pasien dirumah sakit; atau dapat dinyatakan sebagai cara pasien rumah sakit mengevaluasi sampai seberapa besar tingkat kualitas pelayanan dari rumah sakit, sehingga dapat menimbulkan tingkat rasa kepuasan. ${ }^{7}$

Sehingga pada penelitian ini penulis tidak menemukan adanya kesenjangan antara teori dengan kondisi yang ada dilapangan dimana, sebagian sebasar menyatakan puas terhadap pelaksaan komunikasi terapeutik yang dilakukan oleh petugas kesehatan (perawat dan dokter).

\section{SIMPULAN} berikut:

Berdasarkan hasil penelitian dan pembahasan, makan dapat ditarik kesimpulan sebagai

1. Pelaksanaan komunikasi terapeutik pada pada pemasangan infus di Ruang UGD Rumah Sakit Tentara Ciremai Kota Cirebon tahun 2013 berada kategori cukup 33 responden $(42,3 \%)$.

2. Kepuasan pasien di Ruang UGD Rumah Sakit Tentara Ciremai Kota Cirebon tahun 2013 sebagian besar pada kategori puas 40 responden $(51,3 \%)$.

3. Ada hubungan pelaksanaan komunikasi terapeutik pada pemasangan infus dengan kepuasan pasien di Ruang UGD Rumah Sakit Tentara Ciremai Kota Cirebon tahun 2013.

\section{SARAN}

1. Bagi Ilmu Keperawatan

Hasil penelitian ini diharapkan dapat digunakan untuk menambah khasanah keilmuan khususnya pada pelaksanaan komunikasi terapeutik antara perawat dengan klien.

2. Bagi Perawat

Hasil penelitian ini hendaknya dipraktikan oleh perawat dalam melakukan komunikasi terapeutik sehingga kepuasan pasien terhadap pelayanan di Rumah Sakit Ciremai dapat meningkat.

3. Bagi Rumah Sakit

Pihak rumah sakit hendaknya menganjurkan pelaksanaan komunikasi terapeutik bagi perawat saat melakukan tindakan asuhan keperawatan pemasangan infus sehingga pelaksanaan komunikasi antara perawat dengan klien dapat berjalan dengan baik. 
4. Pasien

Pasien hendaknya melakukan komunikasi dengan baik agar perawat dapat melakukan asuhan keperawatan dengan baik dan maksimal.

5. Bagi peneliti Lain

Dapat digunakan sebagai bahan penelitian selanjutnya, khususnya mengenai faktor-faktor yang mempengaruhi tingkat kepuasan pasien terhadap komunikasi terapeutik oleh perawat.

\section{DAFTAR PUSTAKA}

1. Suryawati, S. Improving access to narcotic analgesics: the international control system and options for quantification method. Jurnal Manajemen Pelayanan Kesehatan;2011

2. J. Supranto. "Pengukuran Tingkat kepuasan Pelanggan".Jakarta:Rineka Cipta;2003

3. Kotler, Philip. Manajemen Pemasaran, Analisis, Perencanaan, Implementasi dan Pengendalian,

Jilid 2. Jakarta:Penerbit Erlangga;2004

4. Notoatmodjo,Soekidjo. Metodologi Penelitian Kesehatan. Cetakan II. Edisi Revisi.Jakarta: Rineka Cipta;2005

5. Arikunto. Prosedur Penelitian suatu Pendekatan Praktek. Jakarta: Adi Mahastya;2006

6. Abdul, N. dkk. Komunikasi dalam Keperawtan: Teori dan Aplikasi. Jakarta: Salemba Medika.Komunikasi Untuk Perawat. Jakarta: EGC;2009

7. Budiastuti. Kepuasan Pasien Terhadap Pelayanan Rumah Sakit. Jakarta: EGC;2002 